\title{
Potencial de utilização de Azospirillum brasilense e ácido indolbutírico no enraizamento de estacas de jasmim-amarelo
}

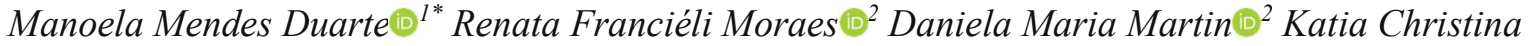 \\ Zuffellato-Ribas ${ }^{2}$
}

${ }^{1}$ Universidade Federal do Paraná, Av. Pref. Lothário Meissner, 632, Jardim Botânico, CEP 80210-170, Curitiba, PR, Brasil ${ }^{2}$ Universidade Federal do Paraná, Rua dos Funcionários, 1540, Juvevê CEP 80035-050, Curitiba-PR, Brasil

Original Article
*Corresponding author:
manu-
florestal@hotmail.com
Palavras-chave:
Auxinas
Bactérias promotoras do crescimento

Espécies ornamentais

Jasminum mesnyi

Propagação vegetativa

Keywords:

Auxins

Growth promoting bacteria

Ornamental species

Jasminum mesnyi

Vegetative propagation

Received in

2019/05/16

Accepted on

2020/02/16

Published in

2020/03/04

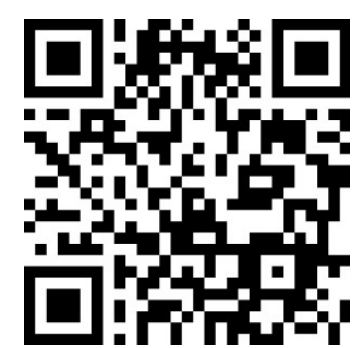

DOI:

http://dx.doi.org/10.34062/af s.v7i1.8376
RESUMO: O jasmim-amarelo (Jasminum mesnyi Hance) é um arbusto perene, semi-herbáceo, que possui folhas densas e flores solitárias de cor amarela. Em virtude do potencial ornamental da espécie esse estudo teve como objetivo avaliar a influência de Azospirillum brasilense e do ácido indolbutírico (IBA) na rizogênese de estacas de Jasminum mesnyi. Para tanto, brotações foram coletadas preparandose estacas com $6 \pm 0,2 \mathrm{~cm}$ de comprimento e mantendo-se um par de folhas reduzidas à metade. Após a desinfestação, as bases das estacas foram tratadas com IBA $(0$, 1000 e $1500 \mathrm{mg} \mathrm{L}^{-1}$ ) e com solução inoculante de $A$. brasilense (concentrado e diluído 1:1), sendo os propágulos plantados em tubetes com vermiculita e mantido em casa de vegetação. Após 100 dias foram avaliadas a porcentagem de enraizamento, número de raízes por estaca, comprimento médio das 3 maiores raízes por estaca, miniestacas vivas e mortas, presença de calos, emissão de brotação e manutenção de folhas. Os resultados para todas as variáveis não apresentaram diferença estatística ao nível de $5 \%$ de probabilidade pelo teste de Tukey. Os resultados indicam que $J$. mesnyi é de fácil enraizamento, e que os tratamentos com IBA e $A$. brasilense não influenciam no enraizamento da espécie.

\section{Azospirillum brasilense and indolebutyric acid potencial use on rooting of jasmim-amarelo cuttings}

ABSTRACT: The yellow jasmine (Jasminum mesnyi Hance) is a perennial, semiherbaceous shrub with dense leaves and solitary yellow flowers. Because of the potential ornamental this study aimed to evaluate the influence of Azospirillum brasilense and indolebutyric acid (IBA) on Jasminum mesnyi cutting rhizogenesis. For this purpose, cuttings were collected and cutting were prepared with $6 \pm 0.2 \mathrm{~cm}$ of length and keeping a pair of leaves reduced in half. After disinfestation, the cuttings bases were treated with IBA $\left(0,1000\right.$ and $\left.1500 \mathrm{mg} \mathrm{L}^{-1}\right)$ and with inoculant solution of $A$. brasilense (concentrated and diluted 1:1), the propagules being planted in plastic tubes with vermiculite substrate and conditioned in a greenhouse. After 100 days we evaluated the percentage of rooting, number of roots per cutting, average length of the 3 largest roots per cutting, live and dead cuttings, callus, sprouts emission and leaf maintenance. The results showed that all variables did not present statistical difference at the $5 \%$ probability level by the Tukey test. The results indicate that $J$. mesnyi is easily rooted, and that the treatments with $A$. brasilense and IBA do not influence the species rooting. 


\section{Introdução}

Jasminum mesnyi Hance, conhecida popularmente como jasmim-amarelo, se caracteriza por ser uma espécie de grande valor ornamental. Arbusto semi-herbáceo perene, a espécie pertence à família Oleaceae, sendo nativa da China e Índia, (Lorenzi e Souza 1999). Suas folhas são densas, com três folíolos lisos e verde-escuros, as flores solitárias são de cor amarela, dispostas ao longo do ramo e aparecem em abundância entre a primavera e o outono (Lorenzi e Souza 1999). A espécie é amplamente utilizada no paisagismo como cerca viva, sebes ou renques (Lorenzi e Souza 1999; Althaus et al. 2007). Além disto, Carneiro et al. (2009) destacam que o jasmim-amarelo apresenta aptidão para cortinas verdes, como por exemplo as utilizadas em estações de tratamentos de esgoto, em função de seus ramos constituírem um estrato inferior denso na cortina.

Outro fator importante a ser mencionado é que a utilização de $J$. mesnyi vem se destacando no cenário da farmacologia. Estudos sobre o uso medicinal dos constituintes metabólicos do jasmimamarelo se aprofundaram nas últimas décadas, graças aos avanços da biotecnologia, sendo que resultados preliminares apontam um elevado potencial desta espécie na medicina humana, especialmente com relação a capacidade antioxidante, tratamento da diabetes (Borar et al. 2011; Bhushman et al. 2014) e das infecções por helmintos (Dullu 2014).

Os poucos estudos relacionados à propagação vegetativa de $J$. mesnyi observados na literatura apontam que a espécie apresenta um enraizamento relativamente fácil e rápido; entretanto, a utilização de reguladores vegetais, tais como IBA (ácido indolbutírico) e NAA (ácido naftalenoacético), podem promover aumento no comprimento das raízes (Lorenzi e Souza 1999; Althaus et al. 2007; Cruz-Silva et al. 2013), melhorando a qualidade efetiva das mudas produzidas. Mesmo com a utilização e potencialidades, alguns autores mencionam a carência de estudos relacionados ao cultivo e propagação da espécie, que precisam ser melhor determinados de maneira a atender e facilitar a produção de mudas em larga escala (Althaus et al. 2007; Cruz-Silva et al. 2013).

Vários são os fatores a serem considerados para a produção e obtenção de mudas de qualidade, independentemente de sua finalidade e, dentre esses fatores, pode-se citar a utilização de substâncias que auxiliam tanto no enraizamento como no desenvolvimento do sistema radicial, resultando em mudas mais robustas e em menores perdas após o plantio. O ácido indolbutírico (IBA) é a auxina sintética mais utilizada para estimular o enraizamento de propágulos, devido à baixa toxidez para a maioria das espécies (Tronco et al. 2015) e utilizada em larga escala na produção de mudas. Entretanto, há uma atual preocupação em buscar alternativas naturais e de menor custo que apresentem o mesmo desempenho que as auxinas.

Microrganismos, tais como fungos micorrízicos arbusculares e bactérias diazotróficas, têm chamado a atenção por contribuir com um modelo atual de agricultura sustentável (Ferreira et al. 2015; Mariosa et al. 2017). Além disto, outros trabalhos têm reportado o papel destes organismos influenciando no desenvolvimento de raízes adventícias e brotos de plantas aéreas (Melo et al. 2012; Vogel et al. 2014; Abdel-Rahman e El-Naggar 2014). Dentre as bactérias diazotróficas, Azospirillum brasilense se destaca pelo seu reconhecido papel na melhoria do crescimento das plantas (Bashan et al. 2004) e capacidade de sintetização de auxinas (Rosa et al. 2018).

Embora sejam poucos os estudos relacionados a utilização de rizobactérias na propagação vegetativa, é importante conhecer o efeito destes organismos especialmente como uma alternativa orgânica aos reguladores vegetais (Mariosa et al. 2017; Rosa et al. 2018). Assim, o objetivo desse estudo foi avaliar a influência de bactérias promotoras de crescimento (Azospirillum brasilense) e do ácido indolbutírico (IBA) no enraizamento de estacas de Jasminum mesnyi.

\section{Material e Métodos}

O experimento foi realizado entre os meses de agosto e novembro de 2018, nas dependências do Grupo de Estudo e Pesquisa em Estaquia - GEPE, localizado no Centro Politécnico, Setor de Ciências Biológicas, Universidade Federal do Paraná (UFPR), em Curitiba, Paraná.

Os propágulos utilizados foram provenientes de brotações do ano, coletadas em três plantas matrizes de $J$. mesnyi, distribuídas aleatoriamente nos jardins do Centro Politécnico da Universidade Federal do Paraná. As brotações foram coletadas na data da instalação do experimento, nas primeiras horas do dia, sendo o material mantido hidratado em recipientes com água até o preparo das estacas.

As estacas herbáceas foram confeccionadas com 6,0 $\pm 0,2 \mathrm{~cm}$ de comprimento, com corte em bisel na base e reto no ápice, mantendo-se um par de folhas apicais reduzidas pela metade. Após confecção, as estacas passaram por processo de desinfestação, sendo imersas em solução de hipoclorito de sódio $0,5 \%$, por 10 minutos, seguida de lavagem em água corrente por 5 minutos.

Posteriormente, as bases das estacas foram submetidas aos seguintes tratamentos: T1: testemunha, estacas sem tratamento; T2: estacas tratadas por 10 segundos em solução $50 \%$ hidroalcoólica de IBA na concentração de $1000 \mathrm{mg}$ $\mathrm{L}^{-1}$; T3: estacas tratadas por 10 segundos em solução $50 \%$ hidroalcoólica de IBA na concentração de 1500 mg L-1; T4: estacas tratadas por 15 minutos em AZOTotal $50 \% \quad$ (Azospirillum brasilense - 
inoculante diluído em água 1:1) e; T5: estacas tratadas por 15 minutos em AZOTotal 100\% (Azospirillum brasilense - inoculante puro). As estacas foram plantadas em tubetes de polipropileno de $53 \mathrm{~cm}^{3}$, contendo vermiculita em granulometria fina, e então mantidas em casa de vegetação climatizada $\left(24^{\circ} \mathrm{C} \pm 2{ }^{\circ} \mathrm{C}\right.$, com nebulização intermitente e umidade relativa do ar em torno de $90 \%)$.

Após 100 dias da instalação, foram avaliadas as seguintes variáveis: porcentagem de enraizamento (estacas com raízes de pelo menos $2 \mathrm{~mm}$ de comprimento); número de raízes formadas por estaca; comprimento das três maiores raízes por estaca $(\mathrm{cm})$; porcentagem de estacas que emitiram novas brotações (com pelo menos $2 \mathrm{~mm}$ de comprimento); manutenção de folhas originais nas estacas; porcentagem de estacas com calos; porcentagem de estacas vivas (estacas que não enraizaram e não formaram calos, mas permaneceram vivas); e porcentagem de estacas mortas (estacas que se encontravam com tecidos necrosados)

O experimento seguiu a premissa de um delineamento inteiramente casualizado, com cinco tratamentos (concentrações de bactérias promotoras do crescimento e ácido indolbutírico) e quatro repetições de 20 estacas por unidade experimental. Os dados foram submetidos ao teste de Bartlett para verificação da homogeneidade e posteriormente a análise de variância, com a utilização do software RBio. Havendo diferença significativa, a comparação de médias foi realizada por intermédio do teste de Tukey, em nível de $5 \%$ de probabilidade de erro.

\section{Resultados}

De acordo com a análise de variância, os tratamentos aplicados nas estacas de $J$. mesnyi não apresentaram diferenças significativas (Tabela 1). As somas de quadrados e as médias obtidas para as variáveis estudadas estão descritas na Tabela 1. A média geral da porcentagem de enraizamento foi de $92 \%$, sendo que a testemunha apresentou a maior porcentagem de estacas enraizadas (95\%). Com relação ao número médio de raízes, a aplicação de AZOTotal, nas duas concentrações, proporcionou um menor número de raízes nas estacas.

Tabela 1. Análise de variância e teste de médias para porcentagem de enraizamento (EN), número médio de raízes por estacas (NR), comprimento médio das três maiores raízes (CR), emissão de novos brotos (EB) e manutenção de folhas (MF) em estacas de Jasminum mesnyi após 100 dias de plantio, com a utilização de diferentes concentrações de IBA $\left(0,1000\right.$ e $\left.1500 \mathrm{mg} \mathrm{L}^{-1}\right)$ e AZOTotal (concentrações de 50 e $100 \%$ ).

\begin{tabular}{|c|c|c|c|c|c|c|}
\hline \multicolumn{7}{|c|}{ ANOVA - Quadrado Médio } \\
\hline \multirow{2}{*}{ FV } & \multirow{2}{*}{ GL } & EN & NR & CR & EB & MF \\
\hline & & $(\%)^{(\mathrm{ns})}$ & (ns) & $(\mathrm{cm})^{(\mathrm{ns})}$ & $(\%)^{(\mathrm{ns})}$ & $(\%)^{(\mathrm{ns})}$ \\
\hline Tratamentos & 2 & 33,125 & 0,813 & 1,777 & 134,375 & 264,380 \\
\hline Resíduos & 2 & 62,500 & 1,012 & 0,872 & 77,083 & 227,080 \\
\hline Total & 4 & - & - & - & - & - \\
\hline \multicolumn{7}{|c|}{ Teste de Médias } \\
\hline Testemunha & - & 95,00 & 6,89 & 7,31 & 35,00 & 63,80 \\
\hline IBA $1000 \mathrm{mg} \mathrm{L}^{-1}$ & - & 92,50 & 7,00 & 6,04 & 28,80 & 48,80 \\
\hline IBA $1500 \mathrm{mg} \mathrm{L}^{-1}$ & - & 93,70 & 6,56 & 5,90 & 23,80 & 42,50 \\
\hline AZOTotal 50\% & - & 91,30 & 6,40 & 6,10 & 20,00 & 52,50 \\
\hline AZOTotal $100 \%$ & - & 87,50 & 5,86 & 5,54 & 23,80 & 46,20 \\
\hline Média & - & 92,00 & 6,54 & 6,18 & 26,28 & 50,76 \\
\hline $\mathrm{CV} \%$ & - & 8,60 & 15,40 & 15,10 & 33,40 & 50,80 \\
\hline
\end{tabular}

(ns): não significativo em nível de 5\% de probabilidade de erro pelo teste de Tukey; FV: Fonte de variação; GL: Graus de liberdade; CV: Coeficiente de variação.

O tratamento testemunha apresentou maiores médias para comprimento das três maiores raízes $(7,31 \mathrm{~cm})$, emissão de brotações $(35 \%)$ e manutenção de folhas originais (63\%). A inoculação de AZOTotal $100 \%$ ocasionou o menor comprimento de raízes, AZOTotal $50 \%$ repercutiu em menor emissão de brotações e a aplicação de $1500 \mathrm{mg} \mathrm{L}^{-1}$ de IBA a menor média para manutenção de folhas nas estacas de $J$. mesnyi.
Da mesma maneira que para as variáveis anteriores, não foram observadas diferenças estatísticas para a porcentagem de estacas vivas e mortas de $J$. mesnyi após 100 dias de instalação do experimento. A Figura 1 apresenta as médias observadas para as duas variáveis mencionadas. 


\section{Duarte et al.}

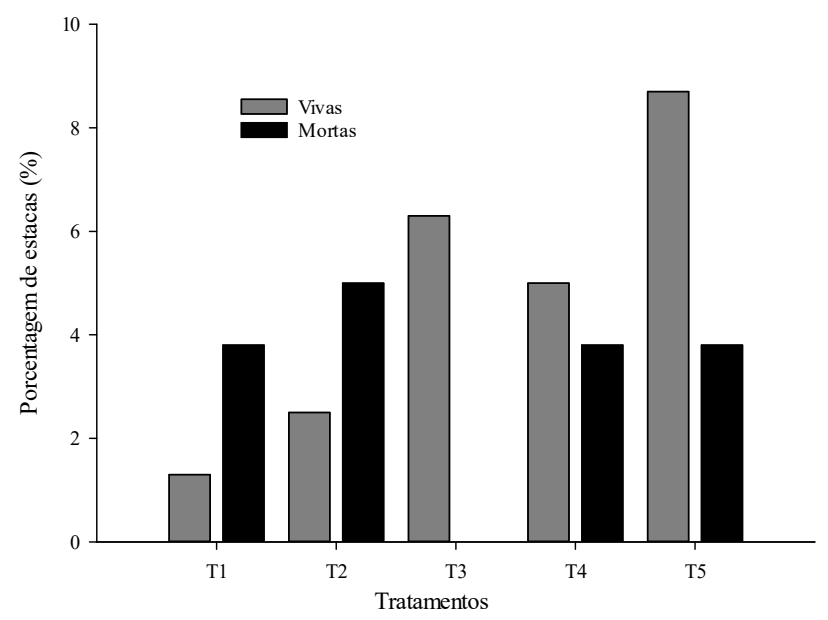

Figura 1. Porcentagem de estacas vivas e mortas de Jasminum mesnyi após 100 dias de plantio, com a utilização de diferentes concentrações de IBA e AZOTotal (T1: $0 \mathrm{mg} \mathrm{L}^{-1}$, T2: $1000 \mathrm{mg} \mathrm{L}^{-1}$; T3: $1500 \mathrm{mg} \mathrm{L}^{-1}$; T4: AZOTotal 50\% e T5: AZOTotal 100\%).

As médias das variáveis estacas vivas e mortas apresentaram percentuais abaixo de $10 \%$ (Figura 1). A aplicação de AZOTotal 100\% resultou na maior média de estacas vivas $(8,7 \%)$, seguida da utilização de $1500 \mathrm{mg} \mathrm{L}^{-1}$ de IBA. O tratamento testemunha apresentou a menor porcentagem de estacas vivas $(1,3 \%)$. A maior porcentagem de mortalidade foi verificada no tratamento com 1000 $\mathrm{mg} \mathrm{L}^{-1}$ de IBA e com a aplicação de $1500 \mathrm{mg} \mathrm{L}^{-1} \mathrm{de}$ IBA não foram observadas estacas mortas. Além disto, não foram observadas estacas com a presença de calos.

\section{Discussão}

Como já caracterizado na literatura por outros autores e baseado na alta porcentagem de enraizamento observado no tratamento testemunha do presente estudo (95\%) é possível afirmar que $J$. mesnyi é uma espécie de fácil enraizamento, não sendo necessário o uso de reguladores vegetais para sua propagação. Além do IBA, Althaus et al. (2007) estudaram a influência do ácido naftaleno acético (NAA) em estacas de $J$. mesnyi e observaram que a aplicação desse regulador também não afeta de maneira positiva a indução de raízes adventícias para a espécie.

Pôde-se perceber ainda que a aplicação de IBA na base das estacas reduziu a porcentagem de enraizamento em comparação ao tratamento testemunha, ainda que não significativamente (Tabela 1). Resultados semelhantes foram observados no estudo de Cruz-Silva et al. 2013. Desta maneira, o efeito estimulador das auxinas exógenas irá depender da sua concentração, pois de acordo com Sauer et al. (2013) a utilização de IBA em elevadas concentrações pode causar toxidez ao vegetal ou efeito inibitório do enraizamento. Assim, pode-se afirmar que a concentração adequada será dependente da espécie e dos teores de auxinas endógenas existentes na planta (Erturk et al. 2010).

Um dos fatores que pode embasar as elevadas porcentagens de enraizamento da espécie é a presença de folhas e gemas nas estacas. Garbuio et al. (2007) ao estudarem o enraizamento do patchouli (Pogostemon clablin) observaram que a presença desses órgãos exerce estímulo para a formação de raízes, sendo esse efeito relacionado à translocação de carboidratos, auxinas e outros cofatores para a base das estacas, compostos estes indispensáveis para o processo de enraizamento.

Ainda, a aptidão para o enraizamento é característica de cada espécie e influenciada por diversos fatores, tais como idade, condições fisiológicas da planta matriz (carboidratos, aminoácidos, auxinas, compostos fenólicos, etc.), período de coleta das estacas, posição no ramo, juvenilidade, tipo de estaca, presença de folhas e gemas, e ainda por fatores ambientais, como água, luminosidade e substrato (Hartmann et al. 2011). Como observado no presente estudo, as matrizes utilizadas para propagação do jasmim-amarelo podem ser consideradas fornecedoras de excelente material vegetativo.

Embora inoculação de $A$. brasilense não tenha apresentado resultados satisfatórios neste estudo, outros autores vêm destacando efeitos positivos e potenciais em sua utilização com relação ao enraizamento, bem como de outros organismos considerados rizobactérias promotoras do crescimento de plantas (RPCP). Exemplo disso são os trabalhos desenvolvidos por Erturk et al. (2010) e Mariosa et al. (2017), onde os autores observaram a produção in vitro de ácido indolacético (IAA), principal auxina endógena sintetizada pelos vegetais, 
por diferentes isolados de RPCP. Quando aplicados com intuito de estimular o enraizamento, os resultados apontam o potencial de uso desses microrganismos e sugerem o desenvolvimento de mais estudos a fim de verificar as possibilidades de produção desses inoculantes de maneira comercial.

No estudo desenvolvido por Rosa et al. (2018) foi possível observar o potencial de uso da associação de $A$. brasilense e IBA. Os autores enfatizam que o efeito do IAA produzido por $A$. brasilense e outras RPCP no enraizamento de estacas lenhosas de Olea europeae L. é similar ao promovido por reguladores vegetais, havendo a possibilidade de substituição dessas substâncias pela inoculação desses grupos de bactérias. De acordo com os autores, pode-se afirmar que as bactérias diazotróficas usadas isoladamente ou associadas a reguladores vegetais podem maximizar o potencial rizogênico de estacas, aumentando a eficiência e reduzindo os custos de produção de mudas.

As variáveis número de raízes por estaca e comprimento médio de raízes são de grande importância quando se pensa na produção de mudas e apresentam íntima relação com a qualidade das mudas e sucesso do plantio. Tanto a aplicação de IBA quanto do AZOTotal não demonstraram aumento dessas variáveis para $J$. mesnyi. Para espécies ornamentais, os relatos sobre uso de $A$. brasilense são escassos; entretanto, para culturas agronômicas, tais como tomate e pimentão, já foram observados alguns benefícios, como o aumento significativo do comprimento de raízes em relação aos tratamentos controle (Madhaiyan et al. 2010).

Embora todos os tratamentos do presente estudo tenham apresentado emissão de brotos, estes valores são considerados baixos (média de 26,3\%) quando se correlaciona com a elevada aptidão de enraizamento da espécie. Devido ao vigor das estacas, era esperado que a energia não utilizada para a rizogênese fosse dispendida para a emissão de novas brotações, para continuidade do processo fotossintético. Somkuwar et al., (2011) destacam que dentre os fatores que podem influenciar a emissão de novos brotos nas estacas estão a presença de gemas axilares, utilização de reguladores vegetais, temperatura, fitossanidade das plantas matrizes e disponibilidade de carboidratos capazes de fornecer energia para a emissão e desenvolvimento destes brotos.

Com relação a variável manutenção de folhas nas estacas, observou-se novamente que o tratamento testemunha apresentou os maiores percentuais. Neste sentido, a presença de folhas favorece o processo de rizogênese e, de acordo com Xavier et al. (2003), esse órgão atua no fornecimento de carboidratos e hormônios necessários ao enraizamento. Os autores ainda destacam que os carboidratos não possuem função regulatória efetiva no enraizamento, e sim são fonte de energia para a síntese de substâncias essenciais para indução das raízes adventícias. Neste sentido, Fragoso et al. (2015) relatam que a presença de folhas foi indispensável para o enraizamento de estacas de Prunus serrulata Lindl. No estudo desenvolvido por Danner et al. (2010) os resultados demonstraram que a baixa porcentagem de manutenção de folhas prejudicou o enraizamento e aumentou a mortalidade das estacas de Vochysia bifalcata Warm.

No presente estudo ainda foi possível relacionar de maneira positiva as baixas porcentagens de mortalidade das estacas com a manutenção das folhas originais, emissão de brotações e elevado vigor das matrizes utilizadas. Outro fator importante a ser destacado é a rizogênese direta de $J$. mesnyi, não sendo observada a presença de calos nas estacas de nenhum dos tratamentos estudados. Hartmann et al. (2011) mencionam que geralmente a presença de calos é observada em espécies de difícil enraizamento, o que não é o caso do jasmim-amarelo. De acordo com Fragoso et al. (2015) a formação ou não de calos está relacionada como uma característica de cada espécie.

Alguns estudos demonstram que os resultados de enraizamento com a utilização de IBA ainda se sobressaem com relação às rizobactérias promotoras do crescimento de plantas, mas os resultados se mostram promissores. $\mathrm{Na}$ busca atual por um modelo mais sustentável de produção, com uso de técnicas e compostos mais naturais, que agridam menos o ambiente, esses organismos surgem como uma alternativa mais ecológica e também de menor custo. No presente estudo não foram encontradas diferenças significativas nos resultados dessas variáveis com a aplicação dos tratamentos com RPCP. Por J. mesnyi se tratar de uma espécie de fácil enraizamento e a avaliação dos resultados terem sido realizadas após 100 dias de plantio não foi possível observar se $A$. brasilense e/ou utilização de IBA resultam em uma mais rápida emissão de raízes e consequente redução de tempo no enraizamento.

\section{Conclusões}

A espécie Jasminum mesnyi pode ser considerada de fácil enraizamento. $\mathrm{O}$ uso de ácido indolbutírico e a inoculação de Azospirilum brasilense em estacas não influenciaram na rizogênese de jasmim-amarelo. Assim, recomendase que mais estudos sejam desenvolvidos com $A$. brasilense, buscando melhorar os resultados para uma utilização efetiva desses organismos na produção de mudas de qualidade, especialmente em espécies com maiores dificuldades de enraizamento e/ou pensar em outras estratégias de uso desses organismos, como a inoculação direta no substrato e estudos objetivando conhecer o desenvolvimento das plantas a campo. 


\section{Agradecimentos}

Agradecemos à Coordenação de Aperfeiçoamento de Pessoal de Nível Superior (CAPES) pela concessão de bolsas de estudo e ao Grupo de Estudo e Pesquisa em Estaquia (GEPE) da Universidade Federal do Paraná pelo apoio.

\section{Referências}

Abdel-Rahman SSA, El-Naggar ARI (2014) Promotion of rooting and growth of some types of Bougainvilleas cutting by plant growth promoting rhizobacteria (PGPR) and arbuscular mycorrhizal fungi (AMF) in combination with indole-3-butyric acid (IBA). International Journal of Science and Research (11): 97-108.

Althaus MM, Leal L, Silveira F, Zuffellato-Ribas KC, Ribas LLF (2007) Influência do ácido naftaleno acético e dois tipos de substrato no enraizamento de estacas de jasmim-amarelo. Revista Ciência Agronômica, 38(5):322-326. Disponível em: $<$ http://ccarevista.ufc

.br/seer/index.php/ccarevista/article/view/123/118>. Acesso em: 02 mai 2019.

Bashan Y, Holguin G, De-Bashan LE (2004) Azospirillum-plant relationships: physiological, molecular, agricultural, and environmental advances (1997-2003). Canadian Journal of Microbiology, 50(8):521-577. doi: https://doi.org/ 10.1139/w04035

Bhushman B, Sardana S, Bansal G (2014) Acute and sub-acute toxicity study of clerodendrum inerme, Jasminum mesnyi Hance and callistemon citrinus. Journal of Acute Disease, 3(4):324-327. doi: 10.1016/S2221-6189(14)60069-X

Borar S, Punia P, Kalia AN (2011) Antioxidant potential of n-butanol fraction from extract of Jasminum mesnyi Hance leaves. Indian Journal of Experimental Biology, 49(1):39-43. Disponível em: $<$ http://nopr.niscair.res.in/bitstream/123456789/107 63/1/IJEB\%2049(1)\%203 9-43.pdf>. Acesso em: 02 mai 2019.

Carneiro C, Scheer MB, Cunha F, Andreoli CV. Manual técnico para implantação de cortinas verdes e outros padrões vegetais em estações de tratamento de esgoto. Curitiba: Sanepar, 2009. v.1. 109p.

Cruz-Silva CTA, Fanti FP, Zuffellato-Ribas KC (2013) Propagação Vegetativa de Jasmim-Amarelo (Jasminum mesnyi Hance) via estaquia. Scientia Agraria, 14(2):77-82. doi: http://dx.doi.org/10.5380/rsa.v14i2.40935

Danner MA, Gubert C, Tagliani MC, ZuffellatoRibas KC (2010) Estaquia semilenhosa de Vochysia bifalcata. Scientia Agraria, 11(6):487-491. doi: http://dx.doi.org/10.5380/rsa.v11 i6.203 95

Dullu V (2014) Anthelmintic activity of ethanolic leaf extract of Jasminum mesnyi. Asian Pacific Journal of Tropic Disease, 4(1):273-275. doi: https://doi.org/10.1016/S2222 1808(14)604 54-0

Erturk Y, Ercisli E, Haznedar A, Cakmakci R (2010) Effects of plant growth promoting rhizobacteria (PGPR) on rooting and root growth of kiwifruit (Actinidfia deliciosa) stem cuttings. Biological Research, 43(1):91-98. doi: http://dx.doi.org/10.4067/S071697602010000 100011

Ferreira GMR, Melloni R, Da Silva LFO, Martins FB, Gonçalves ED (2015) Fungos micorrízicos arbusculares no desenvolvimento de mudas de oliveira (Olea europaea L.) cultivadas no sul de Minas Gerais. Revista Brasileira de Ciência do Solo, 39(2):361-366.

doi: http://dx.doi.org/10.1590/01000683rbcs20140082

Fragoso RO, Witt NGPM, Obrzut VV, Valério S, Zuffellato-Ribas KC, Stuepp CA (2015) Maintenance of leaves and indolebutyric acid in rooting of juvenile Japanese Flowering Cherry cuttings. Revista Brasileira de Ciências Agrárias, 10(1):97-01. doi:10.5039/agraria. v10i1a5111

Garbuio C, Biasi LA, Kowalski APJ (2007) Propagação por estaquia em Patchouli com diferentes números de folhas e tipos de estacas. Scientia Agrária, 8(4):435-438. doi: http://dx.doi.org/10.5380/rsa.v8i4.9893

Hartmann HT, Kester DE, Davies JRFT, Geneve RL (2011) Plant propagation: principles and practices. $8^{\text {th }}$ Edition. São Paulo: Prentice-Hall. 915p.

Lorenzi H, Souza HM (1999) Plantas ornamentais do Brasil: Arbustivas, Herbáceas e Trepadeiras. 2 Edição. Nova Odessa: Editora Plantarum. 818p.

Madhaiyan M, Poonguzhali S, Kang B-G, Lee Y-J, Chung J-B, Sa T-M (2010) Effect of co-inoculation of methylotrophic Methylobacterium oryzae with Azospirillum brasilense and Burkholderia pyrrocinia on the growth and nutrient uptake of tomato, red pepper and rice. Plant Soil, 328:71-82. doi: https://doi.org/10.1007/s1 1104-009-0083-1

Mariosa TN, Melloni EGP, Melloni R, Ferreira GMR, Souza SMP, Silva LFO (2017) Rizobactérias e desenvolvimento de mudas a partir de estacas semilenhosas de oliveira (Olea europeae L.). Revista de Ciências Agrárias, 60(4):302-306. doi: http://dx.doi.org/10.4322/rca. 2447 
Melo LC, Oliveira CV, Manfredi C, Baldani VLD, Ferreira JS (2012) Efeito de bactérias na promoção do enraizamento em clone de eucalipto. Enciclopédia Biosfera, 8(15):736-748. Disponível em:

$<$ http://www.conhecer.org.br/enciclop/2012b/cienci as\%20agrarias/efeito \%20de\%20bacterias.pdf>. Acesso em 02 mai 2019.

Rosa DD, Villa F, Da Silva F, Carbari F (2018) Rooting of semihardwood cuttings of olive: indolbutyric acid, calcium and Azospirillum brasilense. Comunicata Scientiae, 9(1):34-40. doi: https://doi.org/10.14295/cs.v9i1.977

Sauer M, Robert S, Kleine-Vehn J (2013) Auxin: simply complicated. Journal of Experimental Botany, 64(9):2565-2577. doi: https://doi.org/10.1093/jxb/ert139

Somkuwar RG, Bondage DD, Surange MS, Ramteke SD (2011) Rooting behavior, polyphenol oxidase activity, and biochemical changes in grape rootstocks at different growth stages. Turkish Journal of Agriculture and Forestry, 35(3):281-287. doi: 10.3906/tar-0911-62

Tronco KMDQ, Bisognin DA, Fleig FD, Horbach MA (2015) Ex vitro rooting and acclimatization of Ilex paraguariensis A. St Hil. microcuttings. Cerne, 21(3):371-378.

$10.1590 / 01047760201521031523$

Vogel GF, Martinkoski L, Ruzicki M (2014) Efeitos da utilização de Azospirillum brasilense em poáceas forrageiras: importâncias e resultados. Agropecuária Científica no Semiárido, 10(1):1-6. doi: http://dx.doi.org/10.30969/acsa.v10i1.471

Xavier A, Santos GA, Oliveira ML (2003) Enraizamento de miniestaca caulinar e foliar na propagação vegetativa de cedro-rosa (Cedrela fissilis Vell.). Revista Árvore, 27(3):351-356. Disponível em: <http://www.scielo.br/pdf/rarv/ v27n3/a11v27n3>. Acesso em 02 mai 2019. 